\title{
Diversity of free-living prokaryotes on terrestrial and marine Antarctic habitats
}

3 Amanda Gonçalves Bendia ${ }^{1 *}$, Julio Cezar Fornazier Moreira ${ }^{1}$, Juliana Correa Neiva Ferreira ${ }^{1}$,

4 Renato Gamba Romano ${ }^{1}$, Ivan Gonçalves de Castro Ferreira ${ }^{1}$, Diego Castillo Franco ${ }^{1}$, Heitor

5 Evangelista ${ }^{2}$, Rosalinda Carmela Montone ${ }^{3}$, Vivian Helena Pellizari ${ }^{1}$

$7 \quad{ }^{1}$ Departamento de Oceanografia Biológica, Instituto Oceanográfico, Universidade de São Paulo 8 (USP). Praça do Oceanográfico, 191. CEP: 05508-900 São Paulo, SP, Brazil.

9 Instituto de Biologia Roberto Alcantara Gomes, Universidade do Estado do Rio de Janeiro 10 (UERJ). CEP: 20550-013, Rio de Janeiro, RJ, Brazil.

11 33 Departamento de Oceanografia Física, Química e Geológica, Instituto Oceanográfico, 12 Universidade de São Paulo (USP). Praça do Oceanográfico, 191. CEP: 05508-900 São Paulo, SP, 13 Brazil.

$17 *$ Corresponding author:

18 Amanda Gonçalves Bendia, e-mail: amandagb@usp.br

19 Address: Departamento de Oceanografia Biológica, Instituto Oceanográfico, Universidade de São

20 Paulo. Praça do Oceanográfico, 191. 05508-120 São Paulo, SP, Brazil. 


\section{Abstract}

Microorganisms in Antarctica are recognized for having crucial roles in ecosystems functioning and biogeochemical cycles. In order to explore the diversity and composition of microbial

28 communities through different terrestrial and marine Antarctic habitats, we analyze 16S rRNA

29 sequence datasets from fumarole and marine sediments, soil, snow and seawater environments.

30 We obtained measures of alpha- and beta-diversities, as well as we have identified the core 31 microbiome and the indicator microbial taxa of a particular habitat. Our results showed a unique

32 microbial community structure according to each habitat, including specific taxa composing each

33 microbiome. Marine sediments harbored the highest microbial diversity among the analyzed

34 habitats. In the fumarole sediments, the core microbiome was composed mainly by thermophiles

35 and hyperthermophilic Archaea, while in the majority of soil samples Archaea was absent. In the 36 seawater samples, the core microbiome was mainly composed by cultured and uncultured orders

37 usually identified on Antarctic pelagic ecosystems. Snow samples exhibited common taxa in 38 comparison to the habitats from the Antarctic Peninsula, which suggests long-distance dispersal 39 processes occurring from the Peninsula to the Continent. This study contributes as a baseline for 40 further efforts on evaluating the microbial responses to environmental conditions and future 41 changes.

43 Keywords: microbial diversity, microbial indicators, core microbiome, Antarctic habitats 


\section{Introduction}

Despite extreme conditions, Antarctica harbors a complex mosaic of microbial habitats (Bowman, 2018). In these habitats, microorganisms play a fundamental role in the food web and in the biogeochemical cycles. Recent studies revealed diverse bacterial and archaeal communities inhabiting terrestrial and marine habitats in Antarctica, showing to be distinct from Arctic and alpine communities (Boetius et al., 2015). Terrestrial habitats for free-living prokaryotes in Antarctica include especially mineral, ornithogenic and geothermal soils, permafrost, lakes, glaciers, snow and rocks. The microbial diversity in these habitats have been firstly described using culture-dependent methods (e.g. Friedmann et al., 1988; Hirsch et al., 1988; Siebert et al., 1996; Siebert and Hirsch, 1988), and most recently, through culture-independent strategies, mainly by 16S rRNA sequencing (e.g. Alekseev et al., 2020; Almela et al., 2021; Archer et al., 2019; Bendia et al., 2018; Franco et al., 2017; Malard et al., 2019). These studies have shown phyla such as Proteobacteria, Actinobacteria, Acidobacteria, Bacteroidetes and Firmicutes as abundant in soils and permafrosts from Antarctic Peninsula (Bottos et al., 2014; Jansson and Taş, 2014), whereas Cyanobacteriia, Flavobacteriia and Alphaproteobacteria were the prevalent classes in snow samples from the Antarctic Plateau (Michaud et al., 2014).

Marine habitats generally include deep and shallow sediments, and water column at both euphotic $(<200 \mathrm{~m})$ and aphotic zones $(>200 \mathrm{~m})$. Signori et al. (2014) studied microbial communities in water column at Bransfield Strait, Southern Ocean, and found Thaumarchaeota, Euryarchaeota and Proteobacteria (Gamma-, Delta-, Beta-, and Alphaproteobacteria) as abundant taxa below $100 \mathrm{~m}$, whereas the dominant phyla above $100 \mathrm{~m}$ were Bacteroidetes and Proteobacteria (mainly Alphaand Gammaproteobacteria). In marine sediments from Admiralty Bay (100-502 m total depth) (King George Island) and adjacent North Bransfield Basin (693-1147 m), Gammaproteobacteria was found as a highly abundant taxa $(>90 \%)$, followed by Alpha- and Deltaproteobacteria, Firmicutes, Bacteroidetes and Actinobacteria (Franco et al., 2017).

Although previous studies have described microbial communities in different environments from Maritime and Continental Antarctica (e.g. Alekseev et al., 2020; Almela et al., 2021; Archer et al., 2019; Bendia et al., 2018; Cavicchioli, 2015; Cowan et al., 2014; Franco et al., 2017; Malard et 
al., 2019; Signori et al., 2014), few have focused on indicating the microbiome across a range of Antarctic habitats. In this study, we aimed to reveal the microbiome of five habitats (fumarole sediment, marine sediment, snow, soil and seawater) at two main Antarctic locations, including Antarctic Peninsula (King George Island and Deception Island) and Continental Antarctica (West Antarctica, $670 \mathrm{~km}$ from geographical South Pole, near Criosfera 1 module). We were able to describe the core microbiome and the microbial indicators of the different Antarctic habitats, contributing as a baseline study for further efforts on evaluating the microbial responses to environmental conditions and future changes.

\section{Methodology}

\subsection{Study area and sampling strategy}

All the samples selected for this study were collected during the Brazilian Antarctic expeditions (OPERANTAR) XXX to XXXV, comprising the years from 2012 to 2017, and were supported by the following projects: Microsfera (CNPq 407816/2013-5), INCT-Criosfera (CNPq 028306/2009 - Criosfera 1 module) and MonitorAntar (USP-IO/MMA-SBF Agreement No. 009/2012). Detailed information is described in Supplementary Table 1.

The samples selected for this study comprise areas located in both Maritime and Continental Antarctica. In addition, samples include 5 different sample types, comprising the following habitats: marine sediment, fumarole sediment, snow, seawater and soil. and Deception Island (S $62^{\circ} 55^{\prime}$, W $60^{\circ} 37^{\prime}$ ), located in the South Shetland archipelago. Samples

112 from King George Island included seawater, marine sediment and soil. Seawater samples were 113 collected at Admiralty Bay near Wanda and Ecology Glaciers, using a Van-Dorn water-sampling 114 bottle. Three water depths were collected and classified as superficial ( 0 - $5 \mathrm{~m})$, intermediate $(\sim 10$ $115 \mathrm{~m})$ and bottom $(\sim 30 \mathrm{~m})$ depths. Approximately $5 \mathrm{~L}$ of water of each sample were filtered on the 
membrane filters. Superficial marine sediments $(0-5 \mathrm{~cm})$ were collected on the east side of

118 Admiralty Bay, near Point Hennequin, using a Van-Veen Grab Sampler. Approximately $200 \mathrm{~g}$ of sediments of each sample were placed into Whirl-Pak bags. Superficial soil samples $(0-5 \mathrm{~cm})$ were collected on the proximities of EACF and then placed into Whirl-Pak bags ( $200 \mathrm{~g})$. Samples from Deception Island comprised surface sediments $(0-5 \mathrm{~cm})$ in an intertidal region near active fumaroles, with temperatures of $110^{\circ} \mathrm{C}$ for FBA1, FBA2 and FBA3, and $112^{\circ} \mathrm{C}$ for FBB1, FBB2 and FBB3. Fumarole sediments were placed into Whirl-Pak bags ( 200 g).

The Continental Antarctica sampling site is located at West Antarctica, $250 \mathrm{~km}$ from the southwest border of the Ronne ice shelf and $670 \mathrm{~km}$ from the geographic South Pole, where the Brazilian module Criosfera 1 is located (S $84^{\circ} 00^{\prime}$, W $\left.079^{\circ} 30^{\prime}\right)$. Snow/firn samples were collected in an aseptic excavated pit structure near the Brazilian module. Six depths were collected between the surface and $200 \mathrm{~cm}$, including $0-40 \mathrm{~cm}(\mathrm{C} 1), 40-85 \mathrm{~cm}(\mathrm{C} 2), 85-110 \mathrm{~cm}(\mathrm{C} 3), 110-160 \mathrm{~cm}$ (Crio4), 160 - $182 \mathrm{~cm}$ (Crio5), 182 - $200 \mathrm{~cm}$ (C6). Approximately $3 \mathrm{~L}$ of water of each sample were filtered in the Criosfera 1 module using a vacuum pump and $0.22 \mu \mathrm{m}$-membrane filters.

All samples collected in this study were immediately frozen at $-20^{\circ} \mathrm{C}$ for molecular analysis. The description of environmental samples, the coordinates and sampling year are detailed in Supplementary Table 1.

\subsection{DNA extraction and sequencing of the $16 \mathrm{~S}$ rRNA gene}

The $0.22 \mu \mathrm{m}$-membrane filters of seawater and snow samples were submitted to DNA extraction 140 using DNeasy PowerWater Kit (Qiagen, Hilden, Germany). For sediment and soil samples, 141 approximately $500 \mathrm{mg}$ were submitted to DNA extraction using DNeasy PowerSoil Kit (Qiagen,

142 Hilden, Germany). Approximately $10 \mathrm{~g}$ of fumarole sediments were submitted to DNA extraction 143 using DNeasy PowerMax Soil Kit (Qiagen, Hilden, Germany). All extractions were performed 144 according to the manufacturer's instructions. Extracted DNA was quantified using Qubit dsDNA 145 HS Assay (Thermo-Fisher Scientific, Waltham, U.S.A.) and Qubit Fluorometer 1.0 (Thermo146 Fisher Scientific, Waltham, U.S.A.). 
148 Total extracted DNA were sequenced using Illumina Miseq paired-end system 2 x 300 bp, with

149 the primers 515F (5'-GTGYCAGCMGCCGCGGTAA-3') and 806R (5'-

150 GGACTACNVGGGTWTCTAAT-3') (Caporaso et al., 2012) for fumarole sediment and snow

151 samples, targeting the V4 region of the $16 \mathrm{~S}$ rRNA gene, and the primers $515 \mathrm{~F}$ (5'-

152 GTGYCAGCMGCCGCGGTAA-3') and 926R (5'- CCGYCAATTYMTTTRAGTTT -3')

153 (Quince et al., 2011) for seawater, soil and marine sediment samples, targeting the V4 and V5

154 regions of the $16 \mathrm{~S}$ rRNA gene. Details of pairs of primers used for each sample are in

155 Supplementary Table 1. Library construction and sequencing were performed by MR DNA

156 (Molecular Research LP, Shallowater, TX, EUA). The library sequencing followed the Earth

157 Microbiome Project protocol (Thompson et al., 2017).

\subsection{Bioinformatics and statistical analyses}

Reads were initially imported into the Quantitative Insights Into Microbial Ecology 2 software (Qiime2) (v.2020.2, https://docs.quime2.org/) (Bolyen et al., 2019) and then evaluated according to quality. To be consistent among the different sequence datasets and pairs of primers used in our study, only forward sequences (R1) were processed, comprising the V4 region of the 16S rRNA gene. Based on the quality scores, the forward reads were truncated at position 230, and trimmed at the position 25 to remove the primer, using the q2-dada2-denoise script. DADA2 software was used to obtain a set of observed amplicon sequence variants (ASVs) (Callahan et al., 2017). Taxonomic classification was performed through feature-classifier classify-sklearn using the Silva v.138 database (Quast et al., 2013; Yilmaz et al., 2014). The alignment was performed by MAFFT v.7 (Katoh et al., 2002), using default parameters and the phylogenetic tree was built by FastTree

171 (Price et al., 2009).

173 The Qiime2 output qza files were imported on R version 4.0.4 (R CORE TEAM) using the 174 qiime2R package (https://github.com/jbisanz/qiime2R). Alpha and beta diversity metrics were 175 computed through the phyloseq package (McMurdie and Holmes, 2012) on R at a rarefied 176 sampling depth of 11,604 sequences. Statistical differences in alpha diversity indices were 177 calculated by comparing sample types and location using the ANOVA test in stats package on R. 178 Beta diversity was measured by weighted Unifrac distance and visualized via NMDS (non-metric 
multidimensional scaling) using the phyloseq package in $\mathrm{R}$ (version 3.6.3). Differences in the microbial community structure among sample types and location were tested by performing a permutational multivariate analysis of variance (PERMANOVA) on the community matrix (Anderson, 2001).

To observe the unique and shared ASVs by each sample type, the taxa abundance table was transformed to presence/absence. The number of shared ASVs by sample types was visualized using an UpSet plot, UpSetR package (Conway and Gehlenborg, 2019). The core microbiome of each sample type was considered as the shared ASVs within the sample type, which was visualized at order level through pie charts. The statistical package IndicSpecies (Cáceres et al., 2020) was used on $\mathrm{R}$ to identify microbial families whose abundance was significantly associated with a sample type.

Sequencing data were deposited in the National Center for Biotechnology Information Sequence Read Archives (SRA) under BioProject IDs XXXXX (IDs will be provided immediately after manuscript acceptance).

\section{Results}

\subsection{Richness and alpha diversity}

We obtained 4,781,877 valid sequences distributed among 5 sample types (habitats), including 3 samples of marine sediment, 6 samples of fumarole sediments, 6 samples of snow/firn, 52 samples of seawater and 27 samples of soil, totalizing 94 samples. A mean of 336 ASVs $(S D \pm 212)$ were detected for each sample. The values of ASVs, richness (Chao1) and alpha diversity (Shannon and InvSimpson) were statistically different $(p<0.05)$ according to sample type, and not by location ( $p=0.96$ for Chao1, $p=0.44$ for Simpson and $p=0.28$ for InvSimpson). Richness and alpha diversity results are represented in Figure 2 and detailed in Supplementary Table 1.

When grouped by location, the richness and alpha diversity values for the Antarctic continent 
346.84 \pm 84.92 (Chao1), 3.78 \pm 0.75 (Shannon) and 16.29 \pm 20.29 (InvSimpson) for Deception Island; $323.72 \pm 213.57$ (Chao1), 3.93 \pm 0.63 (Shannon) and 28.84 \pm 33.58 (InvSimpson) for King George

212 Island.

When grouped by sample types, marine sediment samples exhibited the highest values of richness $215($ Chao $1=1095.24 \pm 276.30[\mathrm{SD}])$ and alpha diversity (Shannon= 6.01 \pm 0.23 ; InvSimpson= $216174.55 \pm 53.05)$, followed by soil samples (Chao1= 453.68 \pm 149.46 ; Shannon $=4.21 \pm 0.57$; 217 InvSimpson= 30.16 \pm 26.14$)$. Fumarole sediments $($ Chao1=349.38 \pm 84.70 ; Shannon= 3.79 \pm 0.74 ; 218 InvSimpson= 16.46 \pm 20.48$)$, snow $($ Chaol= 339.02 \pm 121.31 ; Shannon= 3.60 \pm 0.64 ; InvSimpson= $21910.32 \pm 3.87)$ and seawater $($ Chaol= 210.77 \pm 44.89 ; Shannon= 3.66 \pm 0.33 ; InvSimpson= $19.83 \pm 5.18$ ) exhibited the lowest values of richness and alpha diversity indices.

\subsection{Beta diversity}

Samples were clustered according to sample type and location through the weighted Unifrac distance analysis observed in NMDS (Figure 3). Seawater samples were grouped nearest from each other, as well as marine sediments. Samples of soil, fumarole sediment and snow exhibited a clustering pattern more distant from each other. Based on the PERMANOVA, samples were significantly influenced more by sample type $\left(\mathrm{p}<0.01, \mathrm{R}^{2}=0.61\right)$ than by location $(\mathrm{p}<0.01$, $\left.229 \mathrm{R}^{2}=0.17\right)$.

\subsection{Microbial community composition at phylum level}

233 A total of 29 phyla were classified as abundant ( $>1 \%$ of relative abundance) among our samples 234 (Figure 4). The most abundant phyla in marine sediments were Proteobacteria $(21.8 \pm 1.8 \%[\mathrm{SD}])$, 235 Bacteroidota (19.9 $\pm 5.0 \%)$, Acidobacteriota (14.0 $\pm 2.9 \%)$, Verrucomicrobiota (11.8 $\pm 2.4 \%)$, 236 Actinobacteriota (9.3 $\pm 1.1 \%)$, Chloroflexi (8.4 $2.5 \%)$, Planctomycetota $(4.1 \pm 1.4 \%)$, 237 Gemmatimonadota (3.3 $\pm 1.0 \%)$, Nitrospirota $(2.2 \pm 0.8 \%)$ and Crenarchaeota (1.0 $\pm 0.5 \%)$. In

238 fumarole sediments, abundant phyla were classified as Aquificota $(21.6 \pm 11.5 \%)$, Proteobacteria 239 (21.1 $\pm 13.6 \%)$, Crenarchaeota (13.6 $\pm 9.5 \%)$, Firmicutes (11.3 $\pm 8.2 \%)$, Deinococcota $(6.0 \pm 5.9 \%)$, 240 Actinobacteriota (3.8 $\pm 1.4 \%)$, Patescibacteria (0.02 $\pm 1.2 \%)$, Bacteroidota (1.7 $\pm 1.0 \%)$, Chloroflexi 
241 (1.6 $\pm 1.8 \%)$, Verrucomicrobiota $(1.5 \pm 0.5 \%)$ and Nanoarchaeota $(1.1 \pm 0.7 \%)$. The most abundant 242 phyla in snow samples were Proteobacteria $(77.6 \pm 17.5 \%)$, followed by Actinobacteriota $243(9.0 \pm 14.6 \%)$, Firmicutes $(7.5 \pm 3.9 \%)$ and Bacteroidota $(1.5 \pm 0.8 \%)$. For water samples, only two 244 phyla were abundant: Proteobacteria (62.8 $\pm 5.8 \%)$ and Bacteroidota (35.4 $\pm 5.8 \%)$. Abundant phyla

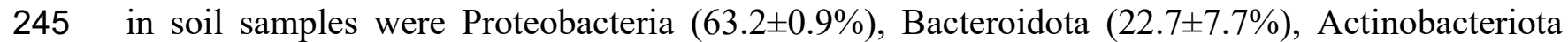
$246 \quad(7.2 \pm 3.4 \%)$ and Acidobacteriota $(3.0 \pm 3.6 \%)$.

\subsection{Shared ASVs and core microbiome}

The number of shared ASVs among sample types are represented in the upset plot of Figure 5. In general, communities from snow shared more ASVs with fumarole sediments (157 ASVs) and seawater (48 ASVs), whereas soil communities shared more ASVs with marine sediments (378 ASVs) and seawater (115 ASVs). The pie charts (Figure 5) represent the taxonomic classification of ASVs (at order level) that were considered the core microbiome of each sample type. The core microbiome indicates the microbial taxa that are particularly widespread within a sample group. The results of core microbiome per sample type are detailed in Supplementary Table 2.

The core microbiome of marine sediments was composed mainly by the orders Chitinophagales (14.8\%), Chthoniobacterales (12.5\%), Burkholderiales (6.6\%), Vicinamibacterales (3.7\%), Chloroflexales (3.2\%), Pyrinomonadales (3.0\%), Gemmatimonadales (3.0\%), among others. For fumarole sediments, the core microbiome was composed by orders such as Desulfurococcales (11.8\%), Hydrogenothermales (9.6\%), Unclassified_Bacteria (5.4\%), Rhodobacterales (4.3\%), Woesearchaeales (3.7\%), Omnitrophales (3.5\%), Nitrococcales $(3.4 \%)$, among others. The core microbiome of snow samples included Pseudomonadales (29.5\%), Burkholderiales (9.0\%), Lactobacillales (6.4\%), Alteromonadales (5.2\%), Bacillales (4.2\%), Chitinophagales (2.9\%), among others. Seawater samples exhibited as the core microbiome the orders Flavobacteriales (40.7\%), SAR11_clade (10.6\%), Cellvibrionales (9.9\%), Rhodobacterales (8.1\%), 268 Oceanospirillales (4.3\%), Burkholderiales (3.7\%), Alteromonadales (2.7\%), Marine_Group_II 269 (1.2\%), among others. The core microbiome of soil samples comprised the orders 270 Xanthomonadales (14.4\%), Sphingomonadales (13.8\%), Flavobacteriales $\quad(12.0 \%)$, 271 Chitinophagales (11.8\%), Burkholderiales (9.4\%), Vicinamibacterales (3.5\%), among others. 
272 Finally, the core microbiome when considered all samples was composed by two orders:

273 Xanthomonadales (35.1\%) and Alteromonadales (64.8\%).

\subsection{Microbial indicators for each sample type}

By using the R package IndicSpecies we were able to identify the families significantly associated with each sample type, which are represented in Figure 6 and detailed in Supplementary Table 3. Marine sediments was the sample type which exhibited the highest number of indicators, totalizing 81 families classified within 22 phyla, such as Anaerolineaceae (Chloroflexi), Pyrinomonadaceae (Acidobacteriota), Holosporaceae (Proteobacteria) and Gaiellaceae (Actinobacteria). A total of 12 families were indicators for fumarole sediments: lineage_IV within Elusimicrobiota, Pyrodictiaceae, Hydrogenothermaceae, Candidatus_Zambryskibacteria, Desulfurococcaceae, Candidatus_Nomurabacteria, Acidilobaceae, SAR202_clade, Methylomirabilaceae, Thermaceae, Thermicanaceae and Woesearchaeales. For snow samples, 4 families were considered as indicators, classified as Oleiphilaceae (Proteobacteria), Burkholderiaceae (Proteobacteria), Bifidobacteriaceae (Actinobacteriota) and Exiguobacteraceae (Firmicutes). Eleven families were indicators of seawater samples, which were classified as Parvibaculaceae, OCS116_clade, Cryomorphaceae, OM182_clade, NS7_marine_group, Clade_III (SAR11_clade), Marine_Group_II, Psychromonadaceae, Arcobacteraceae, SAR116_clade and uncultured family. Demequinaceae (Actinobacteriota), Iamiaceae (Actinobacteriota) and Immundisolibacteraceae 293 (Proteobacteria).

\section{Discussion}

In our study, we were able to describe the core microbiome and the microbial indicators of five significant difference of microbial community structure according to each habitat, showing that 
despite geographical distances, the environmental conditions act as strong pressures for selecting specific microbial taxa.

\subsection{Microbiome of marine sediments from King George Island}

306 Globally, marine sediments cover $70 \%$ of Earth's surface and are thought to be a larger biomass 307 reservoir than seawater, counting for 0.18 to $3.6 \%$ of the total living biomass of the Earth 308 (Kallmeyer et al., 2012; Parkes et al., 2014). In Antarctica, the estimation of the microbial biomass 309 in marine sediments is still poorly understood. The microbial abundance in marine sediments is 310 frequently associated with depth patterns, generally decreasing with increasing depth. A recent 311 study estimated a bacterial and archaeal richness in marine sediment between $4.03 \times 10^{4}$ to $3.30 \times$ $31210^{6}$ ASVs (Hoshino et al., 2020). These values were comparable to the richness estimated for 313 topsoil and seawater samples, which comprised $7.88 \times 10^{4}$ to $1.69 \times 10^{7}$, and $3.00 \times 10^{4}$ to $1.69 \times$ $31410^{6}$, respectively (Hoshino et al. 2020). In the present study, marine sediments showed the highest 315 microbial richness $\left(1.09 \times 10^{3}\right.$ ASVs $)$ when compared to the other habitats, but exhibited lower 316 values than those estimated by Hoshino et al. (2020). It is plausible to observe these contrasts 317 between the global estimations for marine sediments and our richness results, since benthic 318 communities in Antarctica have to adapt to the environmental extreme conditions, such as the 319 prevalent low temperatures, freeze and thaw cycles, low nutrient input, and high salinity (Bölter et al., 2002; Convey et al., 2009). These conditions produce narrow microbial niches and demand specific adaptive mechanisms for microbial growth and survival (Cowan et al., 2014).

Also, this pattern probably reflects the more stable temperatures in the sediments (when compared to other Antarctic habitats), where communities should fluctuate little seasonally, and then more microbial taxa could be able to survive. Other possibilities to explain the highest diversity in marine sediments could be due to the contribution of the communities from soil and snow, which reach inlet waters as results of glacier defrost, or due to cell deposition by descendant of pelagic communities, which could be buried and preserved for long periods (Hoshino et al., 2020).

329 The core microbiome of marine sediments from Admiralty Bay (King George Island) had the prevalence of Bacteroidota, Verrucomicrobiota, Acidobacteria, Chloroflexi, Gemmatimonadota and Proteobacteria, in which some members of these phyla have been previously described in marine sediments of the Antarctic Peninsula (Foong et al., 2010; Li et al., 2020; Powell et al., 
2003). Franco et al. (2017) revealed a high prevalence of heterotrophic gammaproteobacterial phylotypes in the marine sediments of Admiralty Bay, but also reported the presence of taxa from Bacteroidota, Verrucomicrobiota, Acidobacteria, Chloroflexi, Gemmatimonadota phyla.

336 Among the microbial families observed as indicators of marine sediments, Anaerolineaceae 337 (Chroloflexi) have been previously described as abundant in marine sediments, being involved 338 with hydrocarbon degradation (Fincker et al., 2020). In addition, we also observed 339 Pyrinomonadaceae as an indicator of marine sediments, which members were previously observed 340 in diesel contaminated soil samples from King George Island (Gran-Scheuch et al., 2020), and also 341 in other extreme environments, such as semi-arid savannah and volcanic soils (Pascual et al., 342 2018). This bacterial family comprises aerobic and chemoheterotrophic mesophiles or 343 thermophiles, capable of growing in mildly acidophilic environments (Dedysh and Damsté, 2018).

\subsection{Microbiome of fumarole sediments from Deception Island}

346 Previous studies have indicated that temperature is one of the major drivers of microbial 347 communities' diversity and structure (e.g. Price and Giovannelli, 2017; Sharp et al., 2014). 348 Geothermal and hydrothermal ecosystems have been considered as "open-air" laboratories for revealing the responses of microbial communities to temperature gradients (e.g. Antranikian et al., 2017; Bendia et al., 2018; Ward et al., 2017). One of the most interesting ecosystems to explore temperature-adapted extremophiles (psychrophiles, thermophiles, and hyperthermophiles) are the polar volcanoes, where we can find extreme temperature and geochemical gradients over very short distances (Herbold et al., 2014). In Antarctica, a recent study showed that Deception Island volcano harbor different extremophilic lineages, which were strongly driven by steep temperature gradients (from 0 to $98^{\circ} \mathrm{C}$ ) (Bendia et al., 2018).

In our study, the fumarole sediments from Fumarole Bay on Deception Island, which comprised the temperatures of $110{ }^{\circ} \mathrm{C}$ and $112^{\circ} \mathrm{C}$, exhibited as the core microbiome mostly bacterial and archaeal lineages related to thermophiles and hyperthermophiles, such as those within the orders

360 Hydrogenothermales, Sulfobacilalles, Desulfurococcales and Thermales. Further, the indicator 361 families of fumarole sediments belong to thermophiles and hyperthermophiles (Pyrodictiaceae and 362 Hydrogenothermaceae), and to spore-forming bacteria from Firmicutes phylum 363 (Carnobacteriaceae). Pyrodictiaceae comprises members which are autotrophic anaerobes, 
hydrogen-oxidizers, denitrifiers and iron-reducers, whereas Hydrogenothermaceae are usually aerobes or anaerobes, autotrophs, sulfur-oxidizers and denitrifiers (Zeng et al., 2021). Our results indicate that, despite the geographic isolation and the predominantly cold habitats in Antarctica, the hyperthermophilic temperatures act as strong pressures on selecting hyperthermophilic lineages, which showed to be widespread across these fumaroles, as also observed by Bendia et al. (2018). By comparing Deception communities with continental geothermal systems in Antarctica, such as Tramway Ridge in Mount Erebus (Herbold et al., 2014; Soo et al., 2009), few taxa are shared, mainly related to Chloroflexi and Planctomycetes. Pyrodictiaceae and Hydrogenothermaceae lineages were found in geothermal systems, and in shallow and deep-sea hydrothermal vents, such as those in Mariana Volcanic Arc (Nakagawa et al., 2006), Manus Basin, New Guinea (Takai et al., 2001), Vulcano, Italy (Stetter et al., 1983), Tachibana Bay, Japan (Takai and Sako, 1999), and near Tonga subduction zone in the Southwestern Pacific (Ferrera et al., 2014).

\subsection{Microbiome of snow from West Continental Antarctica}

The continental snow represents a dynamic habitat where microorganisms encounter low temperatures, variability in surface UV radiation and limited water and nutrients availability (Larose et al., 2013). Previous studies, including from non-polar environments, identified Proteobacteria, Bacteroidetes, Firmicutes and Cyanobacteria as the dominant taxa in snow habitats in Antarctica (Antony et al., 2016; Lopatina et al., 2016; Malard et al., 2019; Michaud et al., 2014; Yan et al., 2012), Arctic (Harding et al., 2011; Hell et al., 2013; Larose et al., 2013; Maccario et al., 2014), Austria (Battin et al., 2001), Canada (Boyd et al., 2011) and Svalbard (Zarsky et al., 2013). Although previous studies investigated Antarctic snow, few have focused on microbial diversity and distribution, with these studies limited to specific locations leaving the vast majority of the continent unexplored (Boetius et al., 2015; Hodson et al., 2017; Luo et al., 2020). as the core microbiome bacterial lineages related to Proteobacteria, especially Alphaproteobacteria

391 and Gammaproteobacteria, and also several orders related to heterotrophs, such as

392 Alteromonadales, Bacillales, Burkholderiales and Chitinophagales, which is in accordance with 393 previous studies on the Antarctic snow microbial community (Michaud et al., 2014; Antony et al., 394 2016; Lopatina et al., 2016). We detected one archaeal taxa as the core microbiome in snow 
samples, assigned within the order Nitrosopumilales (Crenarchaeota), while a previous study (Antony et al., 2016) identified only Halobacteriaceae (Euryarchaeota) in snow samples from East Antarctica. The detection of Nitrosopumilales across a variety of temperature and saline gradients, suggests that its members have the ability to adapt to hot and cold habitats, as well as to terrestrial and marine ecosystems (Bendia et al., 2018; Learman et al., 2016; Lezcano et al., 2019; Pessi et al., 2015). The family indicators for snow samples were Oleiphilaceae, Burkholderiaceae, Bifidobacteriaceae and Exiguobacteraceae, whose members are often aerobes and heterotrophs (Biavati and Mattarelli, 2018; Coenye, 2014; Vishnivetskaya et al., 2009; Yakimov and Golyshin, 2014), and commonly present in soil habitats from Antarctica (Buelow et al., 2016; Chaturvedi et al., 2008; Pearce et al., 2012), except for Oleiphilaceae, which were predominantly found in deep marine sediments and are known to be hydrocarbon degraders (Bacosa et al., 2018; Golyshin et al., 2002).

It is still not clear if the presence of these bacteria and archaea in snow habitats reflects their ability

408 to adapt and survive in extreme conditions (Edwards et al., 2014), or whether their high 409 predominance in other Antarctic ecosystems favors their aeolian dispersion and preservation along 410 surface habitats in the cryosphere (Archer et al., 2019). Previous studies suggested that soil 411 microorganisms are the primary sources of snow microbial communities of the West Greenland 412 Ice Sheet (Cameron et al., 2015) and Arctic (Cuthbertson et al., 2017; Šantl-Temkiv et al., 2018).

413 Previous studies indicated the dominance of Proteobacteria and Firmicutes in airborne microbial 414 communities in Antarctica (Bottos et al., 2014; Pearce et al., 2010), and the study by Malard et al., 415 (2019) identified similarities between snow and airborne microbial communities in continental 416 Antarctica, which suggests the importance of long-distance dispersal in seeding continental 417 Antarctic snow ecosystems.

\subsection{Microbiome of soils from King George Island}

420 Although the ice-free areas comprise less than $0.3 \%$ of the total Antarctic area, soils are the most 421 studied microbial habitat in Antarctica (Cowan et al., 2014). Soil habitats represent a wide variety 422 of landforms and geochemistry, in which Proteobacteria and Actinobacteria showed to be 423 dominant (Babalola et al., 2009; Makhalanyane et al., 2013). Archaeal taxa in Antarctic soils 424 showed to be a negligible portion of the total microbial community and have likely a minimal role 425 in soil processes (Cowan et al., 2014). A similar pattern was observed among our soil samples 
426 from King George Island, where Acidobacteriota, Actinobacteriota, Bacteroidota and

427 Proteobacteria were the most abundant phyla, while several heterotrophic bacterial families, such

428 as Pseudomonadales, Flavobacteriales, Cytophagales, Chitinophagales, comprised the core

429 microbiome. Wang et al. (2015) also found the predominance of Proteobacteria, Actinobacteria,

430 Acidobacteria, and Verrucomicrobia in four soil types at Fildes Region, King George Island,

431 including pristine and human-impacted soils. Flavobacteriales members are widespread in

432 terrestrial and marine Antarctic ecosystems, and the genus Flavobacterium have shown to play an

433 important role in remineralization processes mainly due to its strong macromolecular hydrolytic

434 capabilities (McCammon and Bowman, 2000). In contrast to our results, Ramos et al. (2019)

435 showed a dominance of Firmicutes in soils from eleven regions of Admiralty Bay, King George

436 Island. Differences in microbial composition of ecologically comparable soils from King George

437 Island suggest a high level of spatial heterogeneity in prokaryotic diversity, as previously indicated

438 by (Almela et al., 2021).

440 The indicator taxa of soil samples comprised four families, classified as Iamiaceae and 441 Demequinaceae, both belonging to Actinobacteriota phylum and with members isolated from 442 marine environments (Kurahashi et al., 2011; Ue et al., 2011), and NRL2 and 443 Immundisolibacteraceae, which have lineages capable of hydrocarbon degradation (Corteselli et 444 al., 2017). Since our soil samples were collected near Comandante Ferraz Brazilian Antarctic 445 Station, the presence of hydrocarbon degraders might indicate an anthropogenic influence on 446 microbial communities of the surrounding soil. Further, the presence of marine bacteria in soils 447 from King George Island indicates that the ocean might be an important source of biological input 448 to terrestrial environments, as suggested by Chong et al. (2012).

\subsection{Microbiome of seawater from King George Island}

452 Microbial communities along seawater samples from Admiralty Bay were very similar, even when 453 comparing the superficial, intermediate and bottom depths. We observed as the core microbiome 454 several marine orders, such as Alteromonadales, Oceanospirillales, SAR11 clade, 455 Flavobacteriales, Rhodobacterales and the archaeal Marine Group II. These groups also showed 456 to be abundant in shallow waters of the Bransfield Strait (Signori et al., 2018, 2014). 
457 Alteromonadales and Oceanospirillales are known to play an important role in organic carbon

458 degradation by the production of extracellular hydrolytic enzymes (Dang et al., 2009). Some

459 members of Oceanospirillales are also potential chemoautotrophs due to the presence of carbon

460 fixation genes (Calvin Cycle pathway) (DeLorenzo et al., 2012). Although several members of the 461 seawater community from Admiralty Bay were very similar to those found in surface waters of

462 Bransfield Strait (Signori et al., 2018), we did not detect some key taxa, such as those within 463 ammonia-oxidizing Archaea (Thaumarchaeota). Thaumarchaeota lineages were indeed detected 464 in high abundance at surface colder waters of the Southern Ocean $\left(\sim-1{ }^{\circ} \mathrm{C}\right)$ (Signori et al., 2018), 465 which might explain why they were not found in the warmer waters from Admiralty Bay. Further, 466 the high number of Rhodobacterales members in our seawater samples might be explained because 467 they are primary colonizers of particulate organic matter (Dang et al., 2009), which become more available by the processes of glaciers melting during summer.

Among the 11 families assigned as indicators of seawater samples, the majority include uncultivated marine lineages, such as OM182 clade, OCS1116 clade and NS7 marine group, whose metabolic capabilities and roles in biogeochemical cycles are still unknown. The archaeal Marine Group II was also assigned as an indicator of seawater and comprises uncultivated lineages generally more common in surface waters that are potentially phototrophs due to the presence of proteorhodopsin genes (Pereira et al., 2019). Further, several members of the seawater microbiome have shown to contribute to important ecological processes in oligotrophic and cold waters, such as to biomass accumulation and to remineralization of organic matter, so that any environmental

478 changes could strongly affect their functioning in biogeochemical cycles (Tonelli et al., 2021), with possible cascading effects on higher trophic levels (Signori et al., 2018).

\section{Conclusion}

484 In conclusion, our study showed that in Antarctica, the microbiome of each terrestrial and marine 485 habitats here analysed, harbors specific bacterial and archaeal taxa. In fumarole sediments, we 486 found the higher proportion of archaeal taxa, which were mostly related to hyperthermophiles, 487 while in soil samples archaeal lineages were very low abundant or absent. Marine sediments 
showed the highest microbial diversity and then more taxa indicators when compared to the other habitats. Surprisingly, although geographically distant, the continental snow samples exhibited common taxa in comparison to the habitats from the Antarctic Peninsula, which suggests longdistance dispersal processes occurring from the Peninsula to the Continent. Seawater communities

492 showed to harbor similar taxa from those previously described for Bransfield Strait, with the 493 absence of some taxa, such as ammonia-oxidizing Thaumarchaeota members. The description and 494 proposal of key taxa from different Antarctic microbiomes are important for further studies aiming 495 to elucidate which environmental factors drive those microbial communities, as well as to give insights about the interplay of microbial assemblages among the Antarctic ecosystems.

\section{Acknowledgements}

500 We thank the captain and the crew of the research polar vessel Almirante Maximiano, and the 501 chief and team of the Comandante Ferraz Brazilian Antarctic Station for their support in sampling 502 during the OPERANTARs XXX to XXXV. We thank the Criosfera 1 team, in special Dr. 503 Emanuele Kuhn, for their support in sampling during OPERANTAR XXXII. We are very thankful 504 to LECOM's research team, and Rosa C. Gamba for their scientific support.

\section{Funding}

508 This study was part of the projects Microsfera (CNPq 407816/2013-5), INCT-Criosfera (CNPq 509 028306/2009 - Criosfera 1 module) and MonitorAntar (USP-IO/MMA-SBF Agreement No. 510 009/2012), supported by the Brazilian National Council of Technological and Scientific 511 Development (CNPq), Brazilian Ministry of the Environment (MMA) and the Brazilian Antarctic 512 Program (ProAntar). The São Paulo Research Foundation - FAPESP supported the AB 513 Doctorate's fellowship (2012/23241-0).

\section{Conflict of Interest Statement}

516 The authors declare that the research was conducted in the absence of any commercial or financial 517 relationships that could be construed as a potential conflict of interest. 


\section{Figure Legends}

Figure 1. Study locations and sampling sites in the northwest region of Antarctica. The subfigures

521 a, b, c and d represent, respectively, the South Shetland Islands region, the southwest border of the 522 Ronne Ice Shelf, the Admiralty Bay in King George Island and the Deception Island. The red 523 diamonds on the left side represent the three distinct study areas, and the circle represents the 524 sample types by colors (yellow $=$ fumarole sediment, pink $=$ marine sediment, dark blue $=$ 525 seawater, light blue $=$ snow, brown $=$ soil). The map was made by using the Qgis software 526 (QGIS.org 2021) and the Quantarctica data set (Matsuoka et al. 2018).

528 Figure 2. Alpha diversity analyses, including the number of ASVs (observed), the richness index 529 of Chao1, and the alpha diversity indices of Shannon and InviSimpson. Samples are grouped by 530 each habitat (sample type).

Figure 3. Non-metric multidimensional scaling (nMDS) ordination based on weighted UNIFRAC

533 distances. The shapes represent the three main regions in Antarctica and colors the Antarctic 534 habitats (sample types). Stress value $=0.118$.

Figure 4. Microbial community composition grouped by each Antarctic habitat (sample type). The

537 figure shows the relative abundance of bacterial and archaeal taxonomic groups at phylum level. 538 Only phylum with more than $0.1 \%$ of abundance are represented. Sequences were taxonomically 539 classified using the Silva database v. 138.

541 Figure 5. Upset plot composed by ASVs identified among sample types. Circles indicate sample 542 types. Black lines connecting circles indicate shared ASVs. Vertical bars indicate intersection size 543 (number of ASVs) on each set. Pie charts show microbial composition specific to each sample 544 type (orders with abundance $>1 \%$ ) and those shared among all sample types or habitats (core 545 microbiome). 
547 Figure 6. Indicator families identified as significantly associated with each sample type (habitat),

548 calculated using the R package IndicSpecies. The colors represent the phyla classifications of each

549 family.

\section{Supplementary Table Legends}

Supplementary Table 1. Detailed description of environmental samples, including Sample IDs, 554 location, coordinates, sample types, depth, sampling year, name of the project, DNA extraction method, pairs of primers, and diversity indices assigned for each sample.

Supplementary Table 2. Results from core microbiome analysis, at order level, represented as percentages $(\%)$ by each sample type (habitat).

Supplementary Table 3. Results from IndicSpecies analysis, at family level, including the number of $p$ values for each taxa and grouped by sample type (habitat).

\section{References}

Alekseev, I., Zverev, A., Abakumov, E., 2020. Microbial Communities in Permafrost Soils of Larsemann Hills, Eastern Antarctica: Environmental Controls and Effect of
Impact. Microorganisms 8, 1202. https://doi.org/10.3390/microorganisms 8081202

Almela, P., Justel, A., Quesada, A., 2021. Heterogeneity of Microbial Communities in Soils From the Antarctic Peninsula Region. Front. Microbiol. 12. https://doi.org/10.3389/fmicb.2021.628792

Anderson, M.J., 2001. Permutation tests for univariate or multivariate analysis of variance and regression. Can. J. Fish. Aquat. Sci. https://doi.org/10.1139/f01-004

Antony, R., Sanyal, A., Kapse, N., Dhakephalkar, P.K., Thamban, M., Nair, S., 2016. Microbial communities associated with Antarctic snow pack and their biogeochemical implications. Microbiol. Res. 192, 192-202. https://doi.org/10.1016/j.micres.2016.07.004

Antranikian, G., Suleiman, M., Schäfers, C., Adams, M.W.W., Bartolucci, S., Blamey, J.M., Birkeland, N.-K., Bonch-Osmolovskaya, E., da Costa, M.S., Cowan, D., Danson, M., Forterre, P., Kelly, R., Ishino, Y., Littlechild, J., Moracci, M., Noll, K., Oshima, T., Robb, 

Stetter, K.O., 2017. Diversity of bacteria and archaea from two shallow marine hydrothermal vents from Vulcano Island. Extrem. Life Extreme Cond. 21, 733-742. https://doi.org/10.1007/s00792-017-0938-y

Archer, S.D.J., Lee, K.C., Caruso, T., Maki, T., Lee, C.K., Cary, S.C., Cowan, D.A., Maestre, F.T., Pointing, S.B., 2019. Airborne microbial transport limitation to isolated Antarctic soil habitats. Nat. Microbiol. 4, 925-932. https://doi.org/10.1038/s41564-019-0370-4

Babalola, O.O., Kirby, B.M., Le Roes-Hill, M., Cook, A.E., Cary, S.C., Burton, S.G., Cowan, D.A., 2009. Phylogenetic analysis of actinobacterial populations associated with Antarctic Dry Valley mineral soils. Environ. Microbiol. 11, 566-576. https://doi.org/10.1111/j.14622920.2008.01809.x

Bacosa, H.P., Erdner, D.L., Rosenheim, B.E., Shetty, P., Seitz, K.W., Baker, B.J., Liu, Z., 2018. Hydrocarbon degradation and response of seafloor sediment bacterial community in the northern Gulf of Mexico to light Louisiana sweet crude oil. ISME J. 12, 2532-2543. https://doi.org/10.1038/s41396-018-0190-1

Battin, T.J., Wille, A., Sattler, B., Psenner, R., 2001. Phylogenetic and Functional Heterogeneity of Sediment Biofilms along Environmental Gradients in a Glacial Stream. Appl. Environ. Microbiol. 67, 799-807. https://doi.org/10.1128/AEM.67.2.799-807.2001

Bendia, A.G., Signori, C.N., Franco, D.C., Duarte, R.T.D., Bohannan, B.J.M., Pellizari, V.H., 2018. A Mosaic of Geothermal and Marine Features Shapes Microbial Community Structure on Deception Island Volcano, Antarctica. Front. Microbiol. 9. https://doi.org/10.3389/fmicb.2018.00899

Biavati, B., Mattarelli, P., 2018. Chapter 3 - Related Genera Within the Family Bifidobacteriaceae, in: Mattarelli, P., Biavati, B., Holzapfel, W.H., Wood, B.J.B. (Eds.), The Bifidobacteria and Related Organisms. Academic Press, pp. 49-66. https://doi.org/10.1016/B978-0-12805060-6.00003-X

Boetius, A., Anesio, A.M., Deming, J.W., Mikucki, J.A., Rapp, J.Z., 2015. Microbial ecology of the cryosphere: sea ice and glacial habitats. Nat. Rev. Microbiol. 13, 677-690. https://doi.org/10.1038/nrmicro3522

Bölter, M., Beyer, L., Stonehouse, B., 2002. Antarctic Coastal Landscapes: Characteristics, Ecology and Research, in: Beyer, Lothar, Bölter, Manfred (Eds.), Geoecology of Antarctic Ice-Free Coastal Landscapes, Ecological Studies. Springer, Berlin, Heidelberg, pp. 5-15. https://doi.org/10.1007/978-3-642-56318-8_1

Bolyen, E., Rideout, J.R., Dillon, M.R., Bokulich, N.A., Abnet, C.C., Al-Ghalith, G.A., Alexander, H., Alm, E.J., Arumugam, M., Asnicar, F., Bai, Y., Bisanz, J.E., Bittinger, K., Brejnrod, A., Brislawn, C.J., Brown, C.T., Callahan, B.J., Caraballo-Rodríguez, A.M., Chase, J., Cope, E.K., Da Silva, R., Diener, C., Dorrestein, P.C., Douglas, G.M., Durall, D.M., Duvallet, C., Edwardson, C.F., Ernst, M., Estaki, M., Fouquier, J., Gauglitz, J.M., Gibbons, S.M., Gibson, D.L., Gonzalez, A., Gorlick, K., Guo, J., Hillmann, B., Holmes, S., Holste, H., Huttenhower, C., Huttley, G.A., Janssen, S., Jarmusch, A.K., Jiang, L., Kaehler, B.D., 
Kang, K.B., Keefe, C.R., Keim, P., Kelley, S.T., Knights, D., Koester, I., Kosciolek, T., Kreps, J., Langille, M.G.I., Lee, J., Ley, R., Liu, Y.-X., Loftfield, E., Lozupone, C., Maher, M., Marotz, C., Martin, B.D., McDonald, D., McIver, L.J., Melnik, A.V., Metcalf, J.L., Morgan, S.C., Morton, J.T., Naimey, A.T., Navas-Molina, J.A., Nothias, L.F., Orchanian, S.B., Pearson, T., Peoples, S.L., Petras, D., Preuss, M.L., Pruesse, E., Rasmussen, L.B., Rivers, A., Robeson, M.S., Rosenthal, P., Segata, N., Shaffer, M., Shiffer, A., Sinha, R., Song, S.J., Spear, J.R., Swafford, A.D., Thompson, L.R., Torres, P.J., Trinh, P., Tripathi, A., Turnbaugh, P.J., Ul-Hasan, S., van der Hooft, J.J.J., Vargas, F., Vázquez-Baeza, Y., Vogtmann, E., von Hippel, M., Walters, W., Wan, Y., Wang, M., Warren, J., Weber, K.C., Williamson, C.H.D., Willis, A.D., Xu, Z.Z., Zaneveld, J.R., Zhang, Y., Zhu, Q., Knight, R., Caporaso, J.G., 2019. Reproducible, interactive, scalable and extensible microbiome data science using QIIME 2. Nat. Biotechnol. 37, 852-857. https://doi.org/10.1038/s41587-019-0209-9

Bottos, E.M., Scarrow, J.W., Archer, S.D.J., McDonald, I.R., Cary, S.C., 2014. Bacterial Community Structures of Antarctic Soils, in: Cowan, D.A. (Ed.), Antarctic Terrestrial Microbiology: Physical and Biological Properties of Antarctic Soils. Springer, Berlin, Heidelberg, pp. 9-33. https://doi.org/10.1007/978-3-642-45213-0_2

Bowman, J.S., 2018. Identification of Microbial Dark Matter in Antarctic Environments. Front. Microbiol. 9. https://doi.org/10.3389/fmicb.2018.03165

Boyd, E.S., Lange, R.K., Mitchell, A.C., Havig, J.R., Hamilton, T.L., Lafrenière, M.J., Shock, E.L., Peters, J.W., Skidmore, M., 2011. Diversity, Abundance, and Potential Activity of Nitrifying and Nitrate-Reducing Microbial Assemblages in a Subglacial Ecosystem. Appl. Environ. Microbiol. 77, 4778-4787. https://doi.org/10.1128/AEM.00376-11

Buelow, H.N., Winter, A.S., Van Horn, D.J., Barrett, J.E., Gooseff, M.N., Schwartz, E., TakacsVesbach, C.D., 2016. Microbial Community Responses to Increased Water and Organic Matter in the Arid Soils of the McMurdo Dry Valleys, Antarctica. Front. Microbiol. 7. https://doi.org/10.3389/fmicb.2016.01040

Cáceres, M.D., Jansen, F., Dell, N., 2020. indicspecies: Relationship Between Species and Groups of Sites.

Callahan, B.J., McMurdie, P.J., Holmes, S.P., 2017. Exact sequence variants should replace operational taxonomic units in marker-gene data analysis. ISME J. 11, 2639-2643. https://doi.org/10.1038/ismej.2017.119

Cameron, K.A., Hagedorn, B., Dieser, M., Christner, B.C., Choquette, K., Sletten, R., Crump, B., Kellogg, C., Junge, K., 2015. Diversity and potential sources of microbiota associated with snow on western portions of the Greenland Ice Sheet. Environ. Microbiol. 17, 594-609. https://doi.org/10.1111/1462-2920.12446

Caporaso, J.G., Lauber, C.L., Walters, W.A., Berg-Lyons, D., Huntley, J., Fierer, N., Owens, S.M., Betley, J., Fraser, L., Bauer, M., Gormley, N., Gilbert, J.A., Smith, G., Knight, R., 2012. Ultra-high-throughput microbial community analysis on the Illumina HiSeq and MiSeq platforms. ISME J. 6, 1621-1624. https://doi.org/10.1038/ismej.2012.8 
Cavicchioli, R., 2015. Microbial ecology of Antarctic aquatic systems. Nat. Rev. Microbiol. 13, 691-706. https://doi.org/10.1038/nrmicro3549

Chaturvedi, P., Prabahar, V., Manorama, R., Pindi, P.K., Bhadra, B., Begum, Z., Shivaji, S.Y. 2008, n.d. Exiguobacterium soli sp. nov., a psychrophilic bacterium from the McMurdo Dry Valleys, Antarctica. Int. J. Syst. Evol. Microbiol. 58, 2447-2453. https://doi.org/10.1099/ijs.0.2008/000067-0

Chong, C.W., Pearce, D.A., Convey, P., Yew, W.C., Tan, I.K.P., 2012. Patterns in the distribution of soil bacterial 16S rRNA gene sequences from different regions of Antarctica. Geoderma 181-182, 45-55. https://doi.org/10.1016/j.geoderma.2012.02.017

Coenye, T., 2014. The Family Burkholderiaceae, in: Rosenberg, E., DeLong, E.F., Lory, S., Stackebrandt, E., Thompson, F. (Eds.), The Prokaryotes: Alphaproteobacteria and Betaproteobacteria. Springer, Berlin, Heidelberg, pp. 759-776. https://doi.org/10.1007/978-3-642-30197-1_239

Convey, P., Bindschadler, R., di Prisco, G., Fahrbach, E., Gutt, J., Hodgson, D.A., Mayewski, P.A., Summerhayes, C.P., Turner, J., the ACCE Consortium, 2009. Antarctic climate change and the environment. Antarct. Sci. 21, 541-563. https://doi.org/10.1017/S0954102009990642

Conway, J., Gehlenborg, N., 2019. UpSetR: A More Scalable Alternative to Venn and Euler Diagrams for Visualizing Intersecting Sets.

Corteselli, E.M., Aitken, M.D., Singleton, D.R., 2017. Description of Immundisolibacter cernigliae gen. nov., sp. nov., a high-molecular-weight polycyclic aromatic hydrocarbondegrading bacterium within the class Gammaproteobacteria, and proposal of Immundisolibacterales ord. nov. and Immundisolibacteraceae fam. nov. Int. J. Syst. Evol. Microbiol. 67, 925-931. https://doi.org/10.1099/ijsem.0.001714

Cowan, D.A., Makhalanyane, T.P., Dennis, P.G., Hopkins, D.W., 2014. Microbial ecology and biogeochemistry of continental Antarctic soils. Front. Microbiol. 5. https://doi.org/10.3389/fmicb.2014.00154

Cuthbertson, L., Amores-Arrocha, H., Malard, L.A., Els, N., Sattler, B., Pearce, D.A., 2017. Characterisation of Arctic Bacterial Communities in the Air above Svalbard. Biology 6. https://doi.org/10.3390/biology6020029

Dang, H., Zhu, H., Wang, J., Li, T., 2009. Extracellular hydrolytic enzyme screening of culturable heterotrophic bacteria from deep-sea sediments of the Southern Okinawa Trough. World J. Microbiol. Biotechnol. 25, 71-79. https://doi.org/10.1007/s11274-008-9865-5

Dedysh, S.N., Damsté, J.S.S., 2018. Acidobacteria, in: ELS. American Cancer Society, pp. 1-10. https://doi.org/10.1002/9780470015902.a0027685

DeLorenzo, S., Bräuer, S.L., Edgmont, C.A., Herfort, L., Tebo, B.M., Zuber, P., 2012. Ubiquitous Dissolved Inorganic Carbon Assimilation by Marine Bacteria in the Pacific Northwest Coastal Ocean as Determined by Stable Isotope Probing. PLOS ONE 7, e46695. https://doi.org/10.1371/journal.pone.0046695

Edwards, A., Mur, L.A.J., Girdwood, S.E., Anesio, A.M., Stibal, M., Rassner, S.M.E., Hell, K., 
Pachebat, J.A., Post, B., Bussell, J.S., Cameron, S.J.S., Griffith, G.W., Hodson, A.J., Sattler, B., 2014. Coupled cryoconite ecosystem structure-function relationships are revealed by comparing bacterial communities in alpine and Arctic glaciers. FEMS Microbiol. Ecol. 89, 222-237. https://doi.org/10.1111/1574-6941.12283

Ferrera, I., Banta, A.B., Reysenbach, A.-L., 2014. Spatial patterns of Aquificales in deep-sea vents along the Eastern Lau Spreading Center (SW Pacific). Syst. Appl. Microbiol. 37, 442-448. https://doi.org/10.1016/j.syapm.2014.04.002

Fincker, M., Huber, J.A., Orphan, V.J., Rappé, M.S., Teske, A., Spormann, A.M., 2020. Metabolic strategies of marine subseafloor Chloroflexi inferred from genome reconstructions. Environ. Microbiol. 22, 3188-3204. https://doi.org/10.1111/1462-2920.15061

Foong, C.P., Wong Vui Ling, C.M., González, M., 2010. Metagenomic analyses of the dominant bacterial community in the Fildes Peninsula, King George Island (South Shetland Islands). Polar Sci., Antarctic Biology in the 21st Century - Advances in and beyond IPY 4, $263-$ 273. https://doi.org/10.1016/j.polar.2010.05.010

Franco, D.C., Signori, C.N., Duarte, R.T.D., Nakayama, C.R., Campos, L.S., Pellizari, V.H., 2017. High Prevalence of Gammaproteobacteria in the Sediments of Admiralty Bay and North Bransfield Basin, Northwestern Antarctic Peninsula. Front. Microbiol. 8. https://doi.org/10.3389/fmicb.2017.00153

Friedmann, E.I., Hua, M., Ocampo-Friedmann, R., 1988. Cryptoendolithic lichen and cyanobacterial communities of the Ross Desert, Antarctica. Polarforschung 58, 251-259.

Golyshin, P.N., Chernikova, T.N., Abraham, W.-R., Lünsdorf, H., Timmis, K.N., Yakimov, M.M. 2002, n.d. Oleiphilaceae fam. nov., to include Oleiphilus messinensis gen. nov., sp. nov., a novel marine bacterium that obligately utilizes hydrocarbons. Int. J. Syst. Evol. Microbiol. 52, 901-911. https://doi.org/10.1099/00207713-52-3-901

Gran-Scheuch, A., Ramos-Zuñiga, J., Fuentes, E., Bravo, D., Pérez-Donoso, J.M., 2020. Effect of Co-contamination by PAHs and Heavy Metals on Bacterial Communities of Diesel Contaminated Soils of South Shetland Islands, Antarctica. Microorganisms 8, 1749. https://doi.org/10.3390/microorganisms8111749

Harding, T., Jungblut, A.D., Lovejoy, C., Vincent, W.F., 2011. Microbes in High Arctic Snow and Implications for the Cold Biosphere. Appl. Environ. Microbiol. 77, 3234-3243. https://doi.org/10.1128/AEM.02611-10

Hell, K., Edwards, A., Zarsky, J., Podmirseg, S.M., Girdwood, S., Pachebat, J.A., Insam, H., Sattler, B., 2013. The dynamic bacterial communities of a melting High Arctic glacier snowpack. ISME J. 7, 1814-1826. https://doi.org/10.1038/ismej.2013.51

Herbold, C.W., McDonald, I.R., Cary, S.C., 2014. Microbial Ecology of Geothermal Habitats in Antarctica, in: Cowan, D.A. (Ed.), Antarctic Terrestrial Microbiology: Physical and Biological Properties of Antarctic Soils. Springer, Berlin, Heidelberg, pp. 181-215. https://doi.org/10.1007/978-3-642-45213-0_10

Hirsch, P., Hoffmann, B., Gallikowski, C.C., Mevs, U., Siebert, J., Sittig, M., 1988. Diversity and identification of heterotrophic bacteria from Antarctic Rocks of the McMurdo Dry Valleys 
(Ross Desert). Suppl. Hirsch P Al 198837 Divers. Identif. Heterotrophs Antarct. Rocks McMurdo Dry Val. Ross Desert Polarforsch. 5823 261-269 Hdl10013epic29622d001. https://doi.org/10.1594/PANGAEA.763324

Hodson, A.J., Nowak, A., Cook, J., Sabacka, M., Wharfe, E.S., Pearce, D.A., Convey, P., Vieira, G., 2017. Microbes influence the biogeochemical and optical properties of maritime Antarctic snow. J. Geophys. Res. Biogeosciences 122, 1456-1470. https://doi.org/10.1002/2016JG003694

Hoshino, T., Doi, H., Uramoto, G.-I., Wörmer, L., Adhikari, R.R., Xiao, N., Morono, Y., D’Hondt, S., Hinrichs, K.-U., Inagaki, F., 2020. Global diversity of microbial communities in marine sediment. Proc. Natl. Acad. Sci. 117, 27587-27597. https://doi.org/10.1073/pnas.1919139117

Jansson, J.K., Taş, N., 2014. The microbial ecology of permafrost. Nat. Rev. Microbiol. 12, 414425. https://doi.org/10.1038/nrmicro3262

Kallmeyer, J., Pockalny, R., Adhikari, R.R., Smith, D.C., D’Hondt, S., 2012. Global distribution of microbial abundance and biomass in subseafloor sediment. Proc. Natl. Acad. Sci. 109, 16213-16216. https://doi.org/10.1073/pnas.1203849109

Katoh, K., Misawa, K., Kuma, K., Miyata, T., 2002. MAFFT: a novel method for rapid multiple sequence alignment based on fast Fourier transform. Nucleic Acids Res. 30, 3059-3066. https://doi.org/10.1093/nar/gkf436

Kurahashi, M., Fukunaga, Y., Sakiyama, Y., Harayama, S., Yokota, Akira, 2011. Iamia majanohamensis gen. nov., sp. nov., an actinobacterium isolated from sea cucumber Holothuria edulis, and proposal of Iamiaceae fam. nov. Int. J. Syst. Evol. Microbiol. 59, 869-873. https://doi.org/10.1099/ijs.0.005611-0

Larose, C., Dommergue, A., Vogel, T.M., 2013. Microbial nitrogen cycling in Arctic snowpacks. Environ. Res. Lett. 8, 035004. https://doi.org/10.1088/1748-9326/8/3/035004

Learman, D.R., Henson, M.W., Thrash, J.C., Temperton, B., Brannock, P.M., Santos, S.R., Mahon, A.R., Halanych, K.M., 2016. Biogeochemical and Microbial Variation across 5500 $\mathrm{km}$ of Antarctic Surface Sediment Implicates Organic Matter as a Driver of Benthic Community Structure. Front. Microbiol. 7, 284. https://doi.org/10.3389/fmicb.2016.00284

Lezcano, M.Á., Moreno-Paz, M., Carrizo, D., Prieto-Ballesteros, O., Fernández-Martínez, M.Á., Sánchez-García, L., Blanco, Y., Puente-Sánchez, F., de Diego-Castilla, G., GarcíaVilladangos, M., Fairén, A.G., Parro, V., 2019. Biomarker Profiling of Microbial Mats in the Geothermal Band of Cerro Caliente, Deception Island (Antarctica): Life at the Edge of Heat and Cold. Astrobiology 19, 1490-1504. https://doi.org/10.1089/ast.2018.2004

Li, J., Gu, X., Gui, Y., 2020. Prokaryotic Diversity and Composition of Sediments From Prydz Bay, the Antarctic Peninsula Region, and the Ross Sea, Southern Ocean. Front. Microbiol. 11. https://doi.org/10.3389/fmicb.2020.00783

Lopatina, A., Medvedeva, S., Shmakov, S., Logacheva, M.D., Krylenkov, V., Severinov, K., 2016. Metagenomic Analysis of Bacterial Communities of Antarctic Surface Snow. Front. Microbiol. 7, 398. https://doi.org/10.3389/fmicb.2016.00398 
Luo, W., Ding, H., Li, H., Ji, Z., Huang, K., Zhao, W., Yu, Y., Zeng, Y., 2020. Molecular diversity of the microbial community in coloured snow from the Fildes Peninsula (King George Island, Maritime Antarctica). Polar Biol. 43, 1391-1405. https://doi.org/10.1007/s00300020-02716-0

Maccario, L., Vogel, T.M., Larose, C., 2014. Potential drivers of microbial community structure and function in Arctic spring snow. Front. Microbiol. 5. https://doi.org/10.3389/fmicb.2014.00413

Makhalanyane, T.P., Valverde, A., Birkeland, N.-K., Cary, S.C., Marla Tuffin, I., Cowan, D.A., 2013. Evidence for successional development in Antarctic hypolithic bacterial communities. ISME J. 7, 2080-2090. https://doi.org/10.1038/ismej.2013.94

Malard, L.A., Šabacká, M., Magiopoulos, I., Mowlem, M., Hodson, A., Tranter, M., Siegert, M.J., Pearce, D.A., 2019. Spatial Variability of Antarctic Surface Snow Bacterial Communities. Front. Microbiol. 10. https://doi.org/10.3389/fmicb.2019.00461

McCammon, S.A., Bowman, J.P., 2000. Taxonomy of Antarctic Flavobacterium species: description of Flavobacterium gillisiae sp. nov., Flavobacterium tegetincola sp. nov., and Flavobacterium xanthum sp. nov., nom. rev. and reclassification of [Flavobacterium] salegens as Salegentibacter salegens gen. nov., comb. nov. Int. J. Syst. Evol. Microbiol. 50 Pt 3, 1055-1063. https://doi.org/10.1099/00207713-50-3-1055

McMurdie, P.J., Holmes, S., 2012. Phyloseq: a bioconductor package for handling and analysis of high-throughput phylogenetic sequence data. Pac. Symp. Biocomput. Pac. Symp. Biocomput. 235-246.

Michaud, L., Giudice, A.L., Mysara, M., Monsieurs, P., Raffa, C., Leys, N., Amalfitano, S., Houdt, R.V., 2014. Snow Surface Microbiome on the High Antarctic Plateau (DOME C). PLOS ONE 9, e104505. https://doi.org/10.1371/journal.pone.0104505

Nakagawa, T., Takai, K., Suzuki, Y., Hirayama, H., Konno, U., Tsunogai, U., Horikoshi, K., 2006. Geomicrobiological exploration and characterization of a novel deep-sea hydrothermal system at the TOTO caldera in the Mariana Volcanic Arc. Environ. Microbiol. 8, 37-49. https://doi.org/10.1111/j.1462-2920.2005.00884.x

Parkes, R.J., Cragg, B., Roussel, E., Webster, G., Weightman, A., Sass, H., 2014. A review of prokaryotic populations and processes in sub-seafloor sediments, including biosphere:geosphere interactions. Mar. Geol., 50th Anniversary Special Issue 352, 409425. https://doi.org/10.1016/j.margeo.2014.02.009

Pascual, J., Huber, K.J., Overmann, J., 2018. Pyrinomonadaceae, in: Bergey's Manual of Systematics of Archaea and Bacteria. American Cancer Society, pp. 1-4. https://doi.org/10.1002/9781118960608.fbm00310

Pearce, D.A., Hughes, K.A., Lachlan-Cope, T., Harangozo, S.A., Jones, A.E., 2010. Biodiversity of air-borne microorganisms at Halley Station, Antarctica. Extrem. Life Extreme Cond. 14, 145-159. https://doi.org/10.1007/s00792-009-0293-8

Pearce, D.A., Newsham, K., Thorne, M., Calvo-Bado, L., Krsek, M., Laskaris, P., Hodson, A., Wellington, E.M.H., 2012. Metagenomic Analysis of a Southern Maritime Antarctic Soil. 
Front. Microbiol. 3. https://doi.org/10.3389/fmicb.2012.00403

Pereira, O., Hochart, C., Auguet, J.C., Debroas, D., Galand, P.E., 2019. Genomic ecology of Marine Group II, the most common marine planktonic Archaea across the surface ocean. MicrobiologyOpen 8, e00852. https://doi.org/10.1002/mbo3.852

Pessi, I.S., Osorio-Forero, C., Gálvez, E.J.C., Simões, F.L., Simões, J.C., Junca, H., Macedo, A.J., 2015. Distinct composition signatures of archaeal and bacterial phylotypes in the Wanda Glacier forefield, Antarctic Peninsula. FEMS Microbiol. Ecol. 91, 1-10. https://doi.org/10.1093/femsec/fiu005

Powell, S.M., Bowman, J.P., Snape, I., Stark, J.S., 2003. Microbial community variation in pristine and polluted nearshore Antarctic sediments. FEMS Microbiol. Ecol. 45, 135-145. https://doi.org/10.1016/S0168-6496(03)00135-1

Price, M.N., Dehal, P.S., Arkin, A.P., 2009. FastTree: Computing Large Minimum Evolution Trees with Profiles instead of a Distance Matrix. Mol. Biol. Evol. 26, 1641-1650. https://doi.org/10.1093/molbev/msp077

Price, R.E., Giovannelli, D., 2017. A Review of the Geochemistry and Microbiology of Marine Shallow-Water Hydrothermal Vents, in: Reference Module in Earth Systems and Environmental Sciences. Elsevier. https://doi.org/10.1016/B978-0-12-409548-9.09523-3

Quast, C., Pruesse, E., Yilmaz, P., Gerken, J., Schweer, T., Yarza, P., Peplies, J., Glöckner, F.O., 2013. The SILVA ribosomal RNA gene database project: improved data processing and web-based tools. Nucleic Acids Res. 41, D590-D596. https://doi.org/10.1093/nar/gks1219 Pyrosequenced Amplicons. BMC Bioinformatics 12, 38. https://doi.org/10.1186/14712105-12-38

Ramos, L.R., Vollú, R.E., Jurelevicius, D., Rosado, A.S., Seldin, L., 2019. Firmicutes in different soils of Admiralty Bay, King George Island, Antarctica. Polar Biol. 42, 2219-2226. https://doi.org/10.1007/s00300-019-02596-z

Šantl-Temkiv, T., Gosewinkel, U., Starnawski, P., Lever, M., Finster, K., 2018. Aeolian dispersal of bacteria in southwest Greenland: their sources, abundance, diversity and physiological states. FEMS Microbiol. Ecol. 94. https://doi.org/10.1093/femsec/fiy031

Sharp, C.E., Brady, A.L., Sharp, G.H., Grasby, S.E., Stott, M.B., Dunfield, P.F., 2014. Humboldt's spa: microbial diversity is controlled by temperature in geothermal environments. ISME J. 8, 1166-1174. https://doi.org/10.1038/ismej.2013.237

Siebert, J., Hirsch, P., 1988. Characterization of 15 selected coccal bacteria isolated from Antarctic rock and soil samples from the McMurdo-Dry Valleys (South-Victoria Land). Polar Biol. 9, 37-44. https://doi.org/10.1007/BF00441762

Siebert, J., Hirsch, P., Hoffmann, B., Gliesche, C.G., Peissl, K., Jendrach, M., 1996. Cryptoendolithic microorganisms from Antarctic sandstone of Linnaeus Terrace (Asgard Range): diversity, properties and interactions. Biodivers. Conserv. 5, 1337-1363. https://doi.org/10.1007/BF00051982

Signori, C.N., Pellizari, V.H., Enrich-Prast, A., Sievert, S.M., 2018. Spatiotemporal dynamics of 
marine bacterial and archaeal communities in surface waters off the northern Antarctic Peninsula. Deep Sea Res. Part II Top. Stud. Oceanogr., Oceanographic processes and biological responses around Northern Antarctic Peninsula: a 15-year contribution of the Brazilian High Latitude Oceanography Group 149, 150-160. https://doi.org/10.1016/j.dsr2.2017.12.017

Signori, C.N., Thomas, F., Enrich-Prast, A., Pollery, R.C.G., Sievert, S.M., 2014. Microbial diversity and community structure across environmental gradients in Bransfield Strait, Western Antarctic Peninsula. Front. https://doi.org/10.3389/fmicb.2014.00647

Soo, R.M., Wood, S.A., Grzymski, J.J., McDonald, I.R., Cary, S.C., 2009. Microbial biodiversity of thermophilic communities in hot mineral soils of Tramway Ridge, Mount Erebus, Antarctica. Environ. Microbiol. 11, 715-728. https://doi.org/10.1111/j.14622920.2009.01859.x

Stetter, K.O., König, H., Stackebrandt, E., 1983. Pyrodictium gen. nov., a New Genus of Submarine Disc-Shaped Sulphur Reducing Archaebacteria Growing Optimally at $105^{\circ} \mathrm{C}$. Syst. Appl. Microbiol. 4, 535-551. https://doi.org/10.1016/S0723-2020(83)80011-3

Takai, K., Komatsu, T., Inagaki, F., Horikoshi, K., 2001. Distribution of Archaea in a Black Smoker Chimney Structure. Appl. Environ. Microbiol. 67, 3618-3629. https://doi.org/10.1128/AEM.67.8.3618-3629.2001

Takai, K., Sako, Y., 1999. A molecular view of archaeal diversity in marine and terrestrial hot water environments. FEMS Microbiol. Ecol. 28, 177-188. https://doi.org/10.1111/j.15746941.1999.tb00573.x

Thompson, L.R., Sanders, J.G., McDonald, D., Amir, A., Ladau, J., Locey, K.J., Prill, R.J., Tripathi, A., Gibbons, S.M., Ackermann, G., Navas-Molina, J.A., Janssen, S., Kopylova, E., Vázquez-Baeza, Y., González, A., Morton, J.T., Mirarab, S., Zech Xu, Z., Jiang, L., Haroon, M.F., Kanbar, J., Zhu, Q., Jin Song, S., Kosciolek, T., Bokulich, N.A., Lefler, J., Brislawn, C.J., Humphrey, G., Owens, S.M., Hampton-Marcell, J., Berg-Lyons, D., McKenzie, V., Fierer, N., Fuhrman, J.A., Clauset, A., Stevens, R.L., Shade, A., Pollard, K.S., Goodwin, K.D., Jansson, J.K., Gilbert, J.A., Knight, R., 2017. A communal catalogue reveals Earth's multiscale microbial diversity. Nature 551, 457-463. https://doi.org/10.1038/nature24621

Tonelli, M., Signori, C.N., Bendia, A.G., Neiva, J., Ferrero, B., Pellizari, V.H., Wainer, I., 2021. Climate projections for the Southern Ocean reveal impacts in the marine microbial communities following increases in sea surface temperature. Front. Mar. Sci. 8. https://doi.org/10.3389/fmars.2021.636226

Ue, H., Matsuo, Y., Kasai, H., Yokota, A., 2011. Demequina globuliformis sp. nov., Demequina oxidasica sp. nov. and Demequina aurantiaca sp. nov., actinobacteria isolated from marine environments, and proposal of Demequinaceae fam. nov. Int. J. Syst. Evol. Microbiol. 61, 1322-1329. https://doi.org/10.1099/ijs.0.024299-0

Vishnivetskaya, T.A., Kathariou, S., Tiedje, J.M., 2009. The Exiguobacterium genus: biodiversity 
and biogeography. Extremophiles 13, 541-555. https://doi.org/10.1007/s00792-009-02435

Wang, N.F., Zhang, T., Zhang, F., Wang, E.T., He, J.F., Ding, H., Zhang, B.T., Liu, J., Ran, X.B., Zang, J.Y., 2015. Diversity and structure of soil bacterial communities in the Fildes Region (maritime Antarctica) as revealed by 454 pyrosequencing. Front. Microbiol. 6. https://doi.org/10.3389/fmicb.2015.01188

Ward, L., Taylor, M.W., Power, J.F., Scott, B.J., McDonald, I.R., Stott, M.B., 2017. Microbial community dynamics in Inferno Crater Lake, a thermally fluctuating geothermal spring. ISME J. 11, 1158-1167. https://doi.org/10.1038/ismej.2016.193

Yakimov, M.M., Golyshin, P.N., 2014. The Family Oleiphilaceae, in: Rosenberg, E., DeLong, E.F., Lory, S., Stackebrandt, E., Thompson, F. (Eds.), The Prokaryotes: Gammaproteobacteria. Springer, Berlin, Heidelberg, pp. 529-533. https://doi.org/10.1007/978-3-642-38922-1_285

Yan, P., Hou, S., Chen, T., Ma, X., Zhang, S., 2012. Culturable bacteria isolated from snow cores along the $1300 \mathrm{~km}$ traverse from Zhongshan Station to Dome A, East Antarctica. Extrem. Life Extreme Cond. https://doi.org/10.1007/s00792-012-0434-3

Yilmaz, P., Parfrey, L.W., Yarza, P., Gerken, J., Pruesse, E., Quast, C., Schweer, T., Peplies, J., Ludwig, W., Glöckner, F.O., 2014. The SILVA and "All-species Living Tree Project (LTP)" taxonomic frameworks. Nucleic Acids Res. 42, D643-D648. https://doi.org/10.1093/nar/gkt1209

Zarsky, J.D., Stibal, M., Hodson, A., Sattler, B., Schostag, M., Hansen, L.H., Jacobsen, C.S., Psenner, R., 2013. Large cryoconite aggregates on a Svalbard glacier support a diverse microbial community including ammonia-oxidizing archaea. Environ. Res. Lett. 8, 035044. https://doi.org/10.1088/1748-9326/8/3/035044

Zeng, X., Alain, K., Shao, Z., 2021. Microorganisms from deep-sea hydrothermal vents. Mar. Life Sci. Technol. https://doi.org/10.1007/s42995-020-00086-4 
bioRxiv preprint doi: https://doi.org/10.1101/2021.04.27.441673; this version posted April 27, 2021. The copyright holder for this preprint (which was not certified by peer review) is the author/funder, who has granted bioRxiv a license to display the preprint in perpetuity. It is made available under aCC-BY-NC-ND 4.0 International license.

\section{$940 \quad$ Figure 1}

941

\begin{tabular}{|l} 
Samples \\
Sumarole sediment \\
Marine sediment \\
Seawater \\
Snow \\
Soil
\end{tabular}

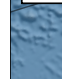
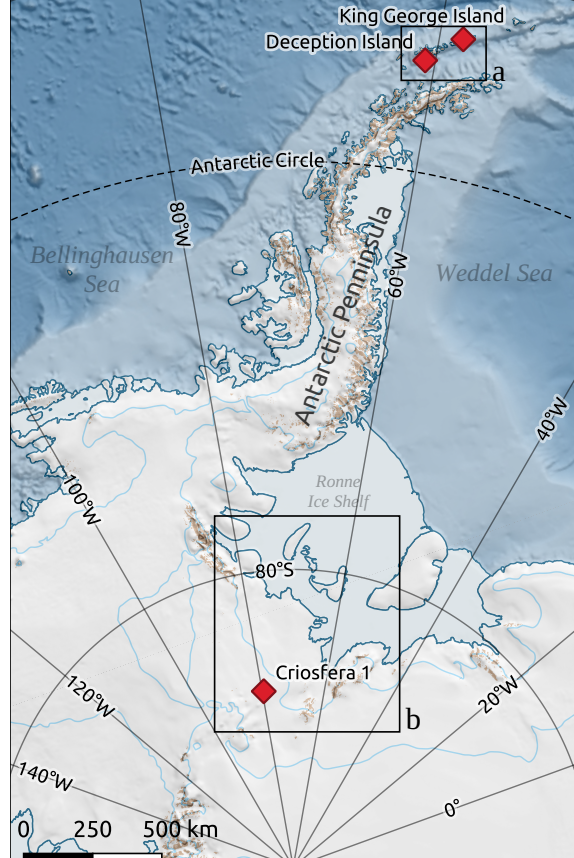

Q

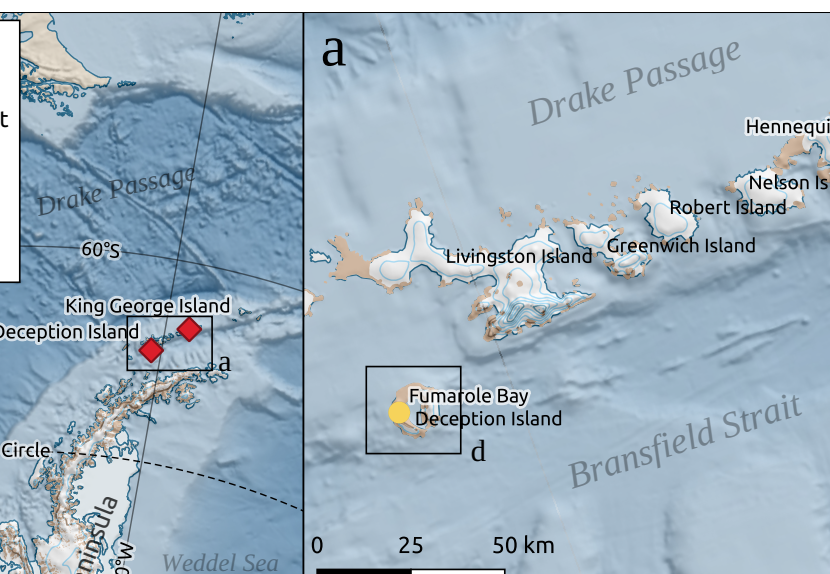

$\mathrm{b}$
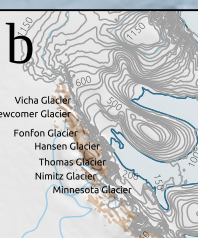

943

944

945

946

947

948

949

950

951

952

953

954

955

956

957

958

959 
Figure 2

961
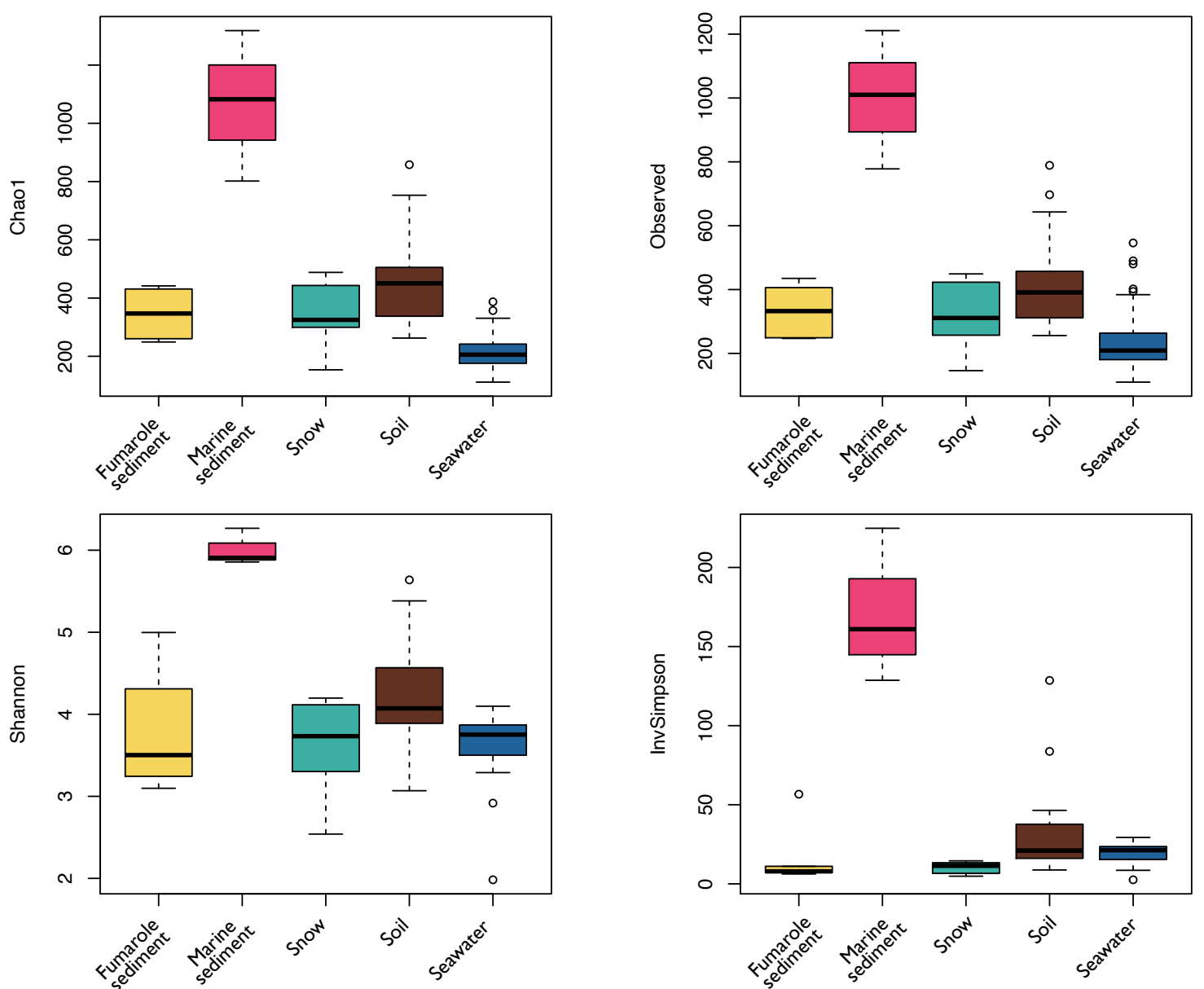

963

964

965

966

967

968

969

970

971

972

973

974

975

976

977 
bioRxiv preprint doi: https://doi.org/10.1101/2021.04.27.441673; this version posted April 27, 2021. The copyright holder for this preprint (which was not certified by peer review) is the author/funder, who has granted bioRxiv a license to display the preprint in perpetuity. It is made available under aCC-BY-NC-ND 4.0 International license.

Figure 3.

980

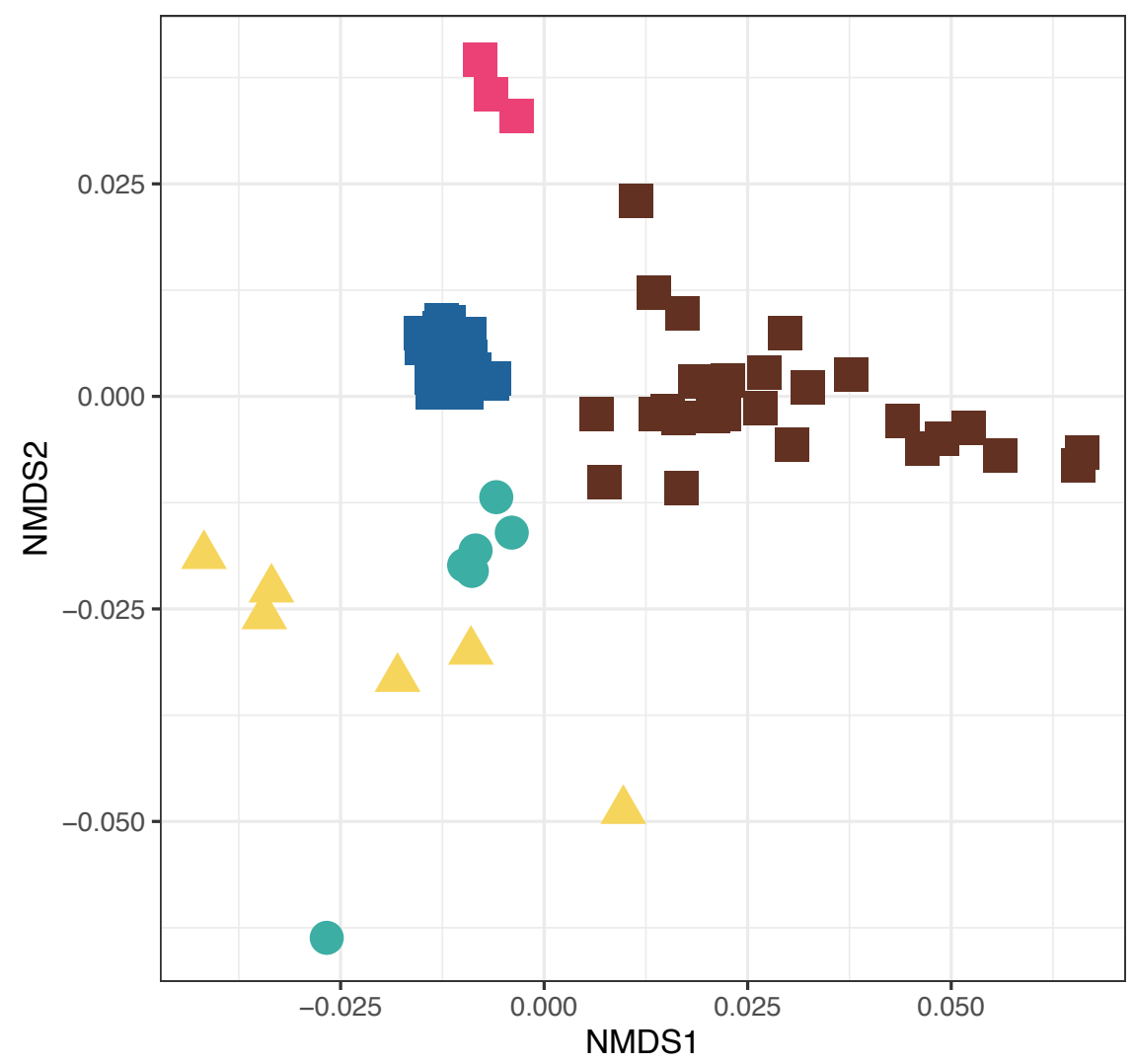

SampleType

- Fumarole sediment

- Marine sediment

- Snow

- Soil

- Seawater

Region

- Antarctic Continent

- Deception Island

- King George Island 
bioRxiv preprint doi: https://doi.org/10.1101/2021.04.27.441673; this version posted April 27, 2021. The copyright holder for this preprint (which was not certified by peer review) is the author/funder, who has granted bioRxiv a license to display the preprint in perpetuity. It is made available under aCC-BY-NC-ND 4.0 International license.

Figure 4

999

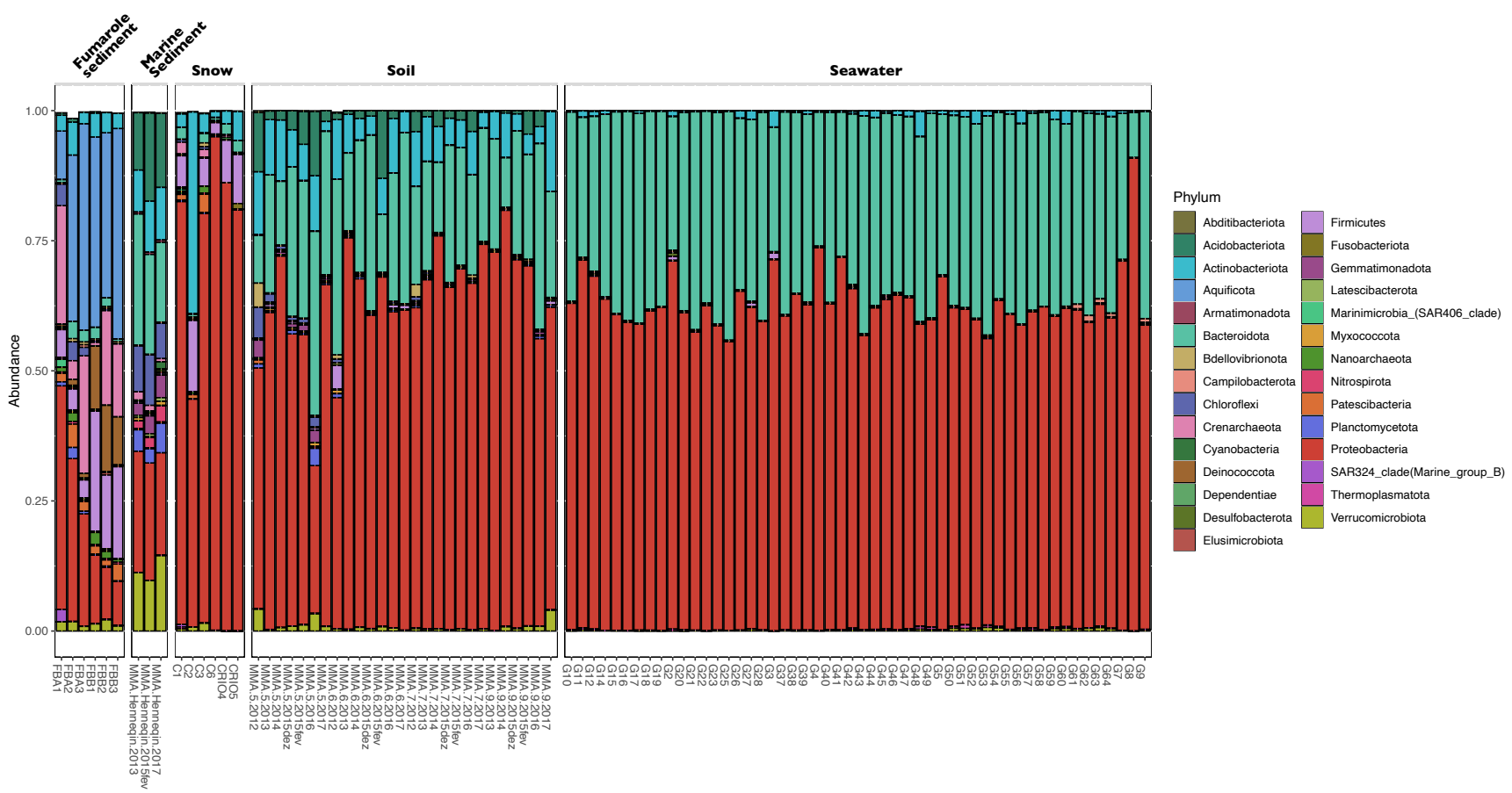

1001

1002

1003

1004

1005

1006

1007

1008

1009

1010

1011

1012

1013

1014

1015

1016

1017

1018

1019

1020

1021

1022 
bioRxiv preprint doi: https://doi.org/10.1101/2021.04.27.441673; this version posted April 27, 2021. The copyright holder for this preprint (which was not certified by peer review) is the author/funder, who has granted bioRxiv a license to display the preprint in perpetuity. It is made available under aCC-BY-NC-ND 4.0 International license.

\section{Figure 5}



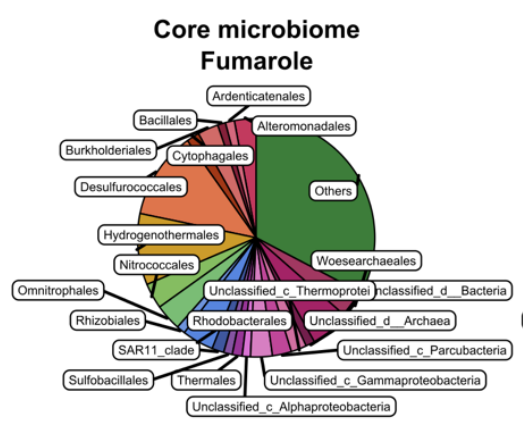

Core microbiome

Soil

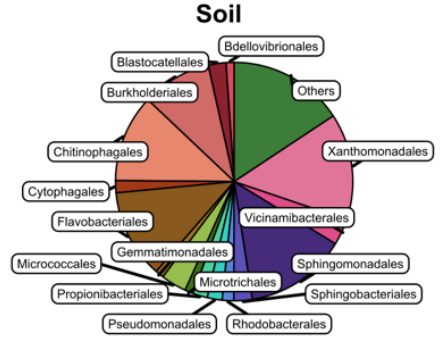

Core microbiome
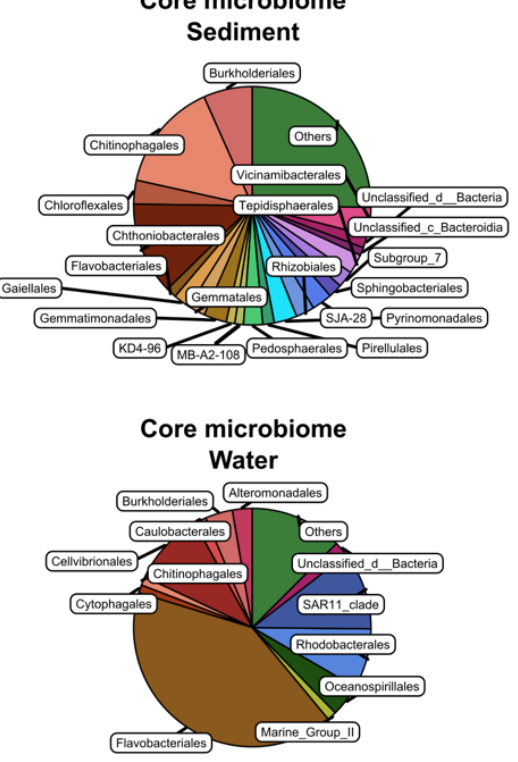

Core microbiome

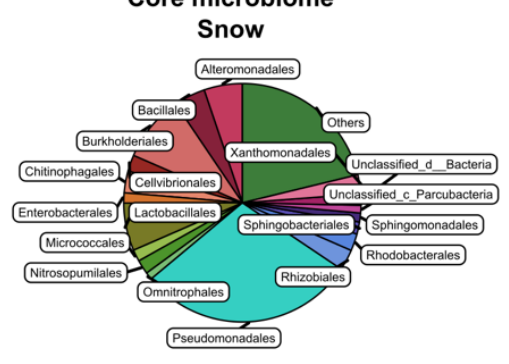

Core microbiome

All

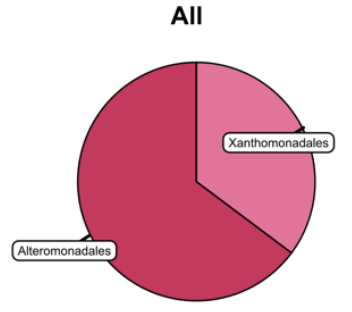


bioRxiv preprint doi: https://doi.org/10.1101/2021.04.27.441673; this version posted April 27, 2021. The copyright holder for this preprint (which was not certified by peer review) is the author/funder, who has granted bioRxiv a license to display the preprint in perpetuity. It is made available under aCC-BY-NC-ND 4.0 International license.

\section{Figure 6}
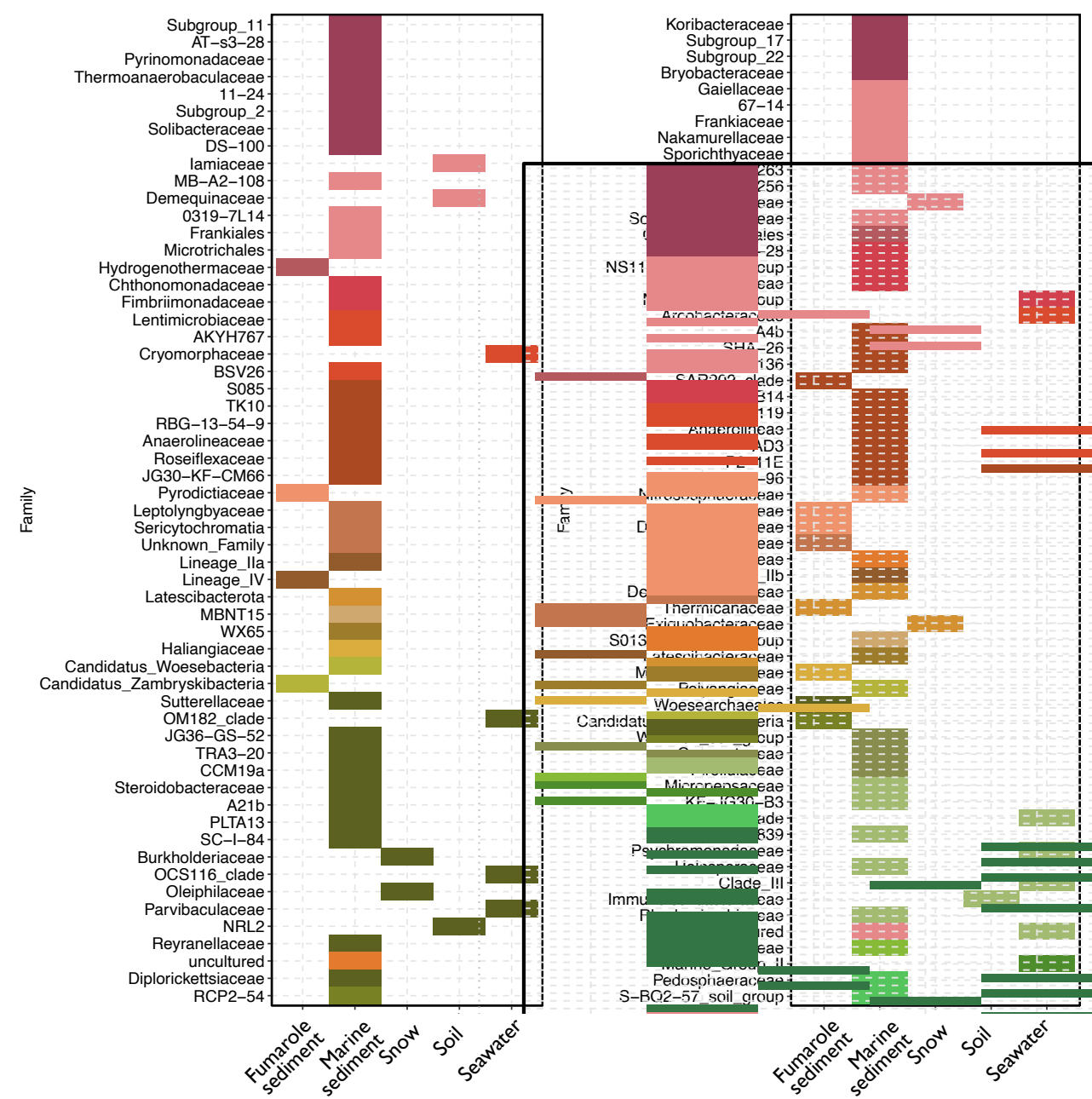

\section{Phylum}

Acidobacteriota

Actinobacteriota

Aquificota

Armatimonadota

Bacteroidota

Campilobacterota

Chloroflexi

Crenarchaeota

Cyanobacteria

Deinococcota

Dependentiae

Desulfobacterota

Elusimicrobiota

Firmicutes

Gemmatimonadota

Latescibacterota

MBNT15

Methylomirabilota

Myxococcota

Nanoarchaeota

Patescibacteria

Planctomycetota

Proteobacteria

RCP2-54

Sumerlaeota

Thermoplasmatota

Verrucomicrobiota 